\title{
GUIDELINES FOR FINER LINES IN THICK FILM CIRCUITRY
}

\author{
P.J.B. BERTRAMS, W. KEUPER, G. KOCH and J.H.C. VAN MOURIK \\ N.V. Philips' Gloeilampenfabrieken, Eindhoven, The Netherlands
}

(Received June 5, 1981; in final form June 26, 1982)

Screen quality, ink, behaviour, printersettings, substrate surface condition and dry and sinterconditions determine print results. For high density printing the quality of each of those parameters is important. It was found, that ink and screen play the most important part.

The metal gauze screen provided with the mask must have a flat surface (roughness $<5 / \mu \mathrm{m}$ ) and an even thickness and gauze tension. For a number of inks the viscosity at low shear-rates defines the fine line capabilities. Some tolerance on printersettings is found to be acceptable. The application of a surfactantson the substrate surface proves to be a solution to gain a better line definition. During levelling the evaporation of solvents at room temperature has to be favoured for an optimum result.

\section{INTRODUCTION}

Applicability reasons and cost considerations augmented the necessity of denser thick film circuitry. The conductor pattern is decisive for the density. The objective of the investigation was to establish, what line resolution could be gained and which conditions must be met with metal gauze screens and commercially available inks for volume production.

\section{THE INVESTIGATIONS}

The influence of the following parameters have been studied:

-ink

- printer and printersetting

- substrate surface conditions (pretreatment of standard thick film substrates)

- screen

- dry and sinter conditions

These parameters will be discussed one by one.

Ink

The inks under considerations were standard type $\mathrm{Ag} \mathrm{Pd}, \mathrm{Ag} \mathrm{Pt}$ and $\mathrm{Au}$ inks and a few special ones ( $\mathrm{Ni}$ inks). To test whether the mechanism of the ink behaviour was understood, some Ag inks were produced in our own laboratory.

From experience it is known that type and lotnumber are insufficient to specify and ink. Every ink under consideration has been measured for its rheological behaviour.

A Rheomat 30 (Contraves) with a concentric measuring system (in accordance with DIN53788) has been used. The measurements were carried out at shear rates between $0.0665 \mathrm{~s}^{-1}$ and $500 \mathrm{~s}^{-1}$. 
The equilibrium values were measured at the various shear rates for most of the inks show thixotropic effects. From some inks the minimum viscosity values were measured after breaking down the thixotropic structure and if possible a yield value has been calculated $\left(\tau_{0}\right)$ according to the formula of Casson $\sqrt{\tau}=\sqrt{\tau_{0}}+\sqrt{\eta_{\mathrm{e}} D}$;;

\section{Screenprint Equipment and Conditions}

In a climatic controlled clean area all print-tests were run on a modified Aremco printer and a modified "de Haart" printer. Tests were run with various squeegee hardnesses, squeegee pressures, squeegee speeds, snap-off distances and with two shapes of squeegee blades.

\section{Screens and Masks}

The screens, $160 \times 190 \mathrm{~mm}$, consists of 230 and 325 mesh stainless steel gauze stretched on an aluminium frame under $45^{\circ}$. The slightly calendered version of the gauze was taken and the mask was placed with its lines parallel to the screen frame. The used masks contained conductor lines of various widths and spacings.

\section{Substrate Material and Surface Treatment}

Standard $95 \% \mathrm{Al}_{2} \mathrm{O}_{3}$ thick film substrates were used for the standard inks and B 270 glass for the inks to be printed on glass.

To trace the influence of surface treatment both types of substrates also have been printed after cleaning of the surface in various ways and after a treatment of the surface with a surfactant.

\section{Dry and Sinter Conditions}

- Levelling took place in air in various ways for different time.

- At $120^{\circ} \mathrm{C}$ the printed substrates were dried in a Hereaus stove with forced air circulation.

- Sintering has been carried out according to standard prescribed methods.

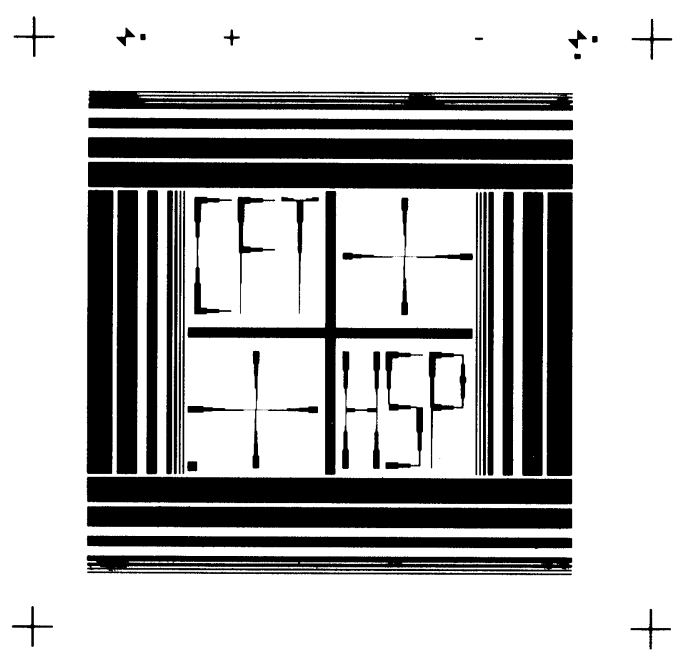

FIGURE 1 Printmask. 


\section{RESULTS}

As a criterion for the print result the deviation between the width of a dried conductor line and its mask width in the screen, the socalled line widening has been used. This line widening played the leading part for classifying inks, screens, print parameters etc.

The following classification has been valid.

$\begin{array}{cc}\text { line widening } & \text { class } \\ <10 / \text { um } & 1 \\ 10-20 / \text { um } & 2 \\ 20-40 / \text { um } & 3 \\ 40-80 / \text { um } & 4 \\ <80 / \text { um } & 5\end{array}$

When the value spread over two classes and the mean value met a class limit, this situation has been noted down as c.q. $2 / 3$.

\section{Discussion of the Results}

It was found during the experiments, that the influence of printer and printersettings was low compared to the influence of ink and screen on the line definition. The discussion will be restricted to the contribution of screen, ink, substrate condition and dry and sinter conditions.

Screen The factors mainly characterizing a screen are meshsize, gauze tension, gauze tension distribution, emulsion layer thickness and flatness of the emulsion layer. Metal gauze has a large mesh relative to the wire diameter. The 230 mesh and the 325 mesh have a usable opening/wire diameter ratio. With high mesh values the problem of clogs increases. For the screens under consideration the gauze tension was between $17 \mathrm{~N} / \mathrm{cm}$ and $30 \mathrm{~N} / \mathrm{cm}$. With a tolerance of $1 \mathrm{~N} / \mathrm{cm}$ over the screen area.

For high density prints the gauze tension must tend to high values, otherwise clogging will occur.

Figure 2 gives a good example of what a good screen should look like in close examination.

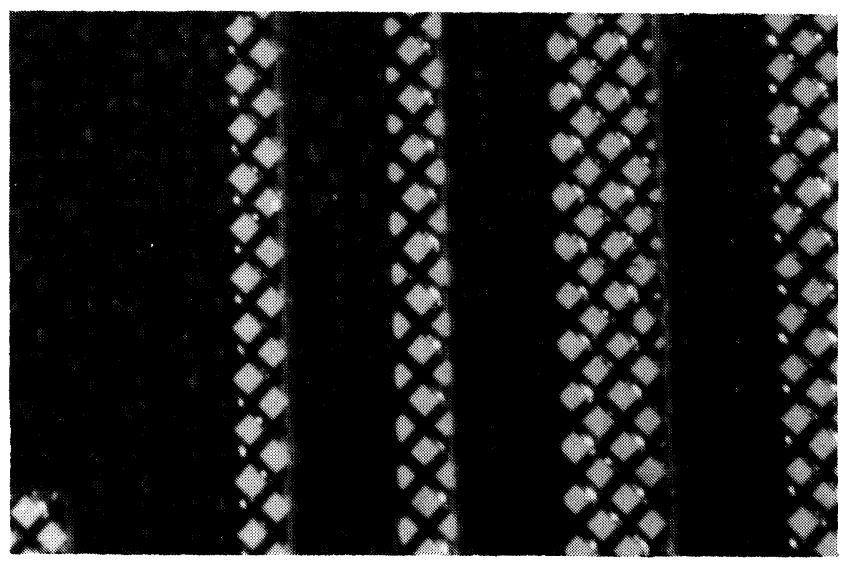

FIGURE 2 A good quality screen. 
TABLE I

Four screens tested on their influence

\begin{tabular}{rrrrrrr}
\hline mesh & $\begin{array}{l}\text { Screen } \\
\text { emuls. }\end{array}$ & number & Ink & $500 \mu \mathrm{m}$ & $250 \mu \mathrm{m}$ & $125 \mu \mathrm{m}$ \\
\hline 325 & $8 \mu \mathrm{m}$ & 951 & B300 & 1 & 1 & 2 \\
325 & $9 \mu \mathrm{m}$ & L1087 & B300 & 1 & 1 & $1 / 2$ \\
230 & $7 \mu \mathrm{m}$ & 814 & & 1 & 2 & 3 \\
325 & $8 \mu \mathrm{m}$ & 951 & & 2 & 2 & 3 \\
325 & $9 \mu \mathrm{m}$ & L1087 & & 2 & 2 & 3 \\
230 & $7 \mu \mathrm{m}$ & 814 & A200 & 2 & 3 & 4 \\
230 & $22 \mu \mathrm{m}$ & 326 & & 3 & 4 & 4 \\
\hline
\end{tabular}

This screen is characterized as follows:

-325 mesh, slightly calendered, stretched under $45^{\circ}$ on the frame

- mask parallel to the frame

- tension between $28 \mathrm{~N} / \mathrm{cm}$ and $29 \mathrm{~N} / \mathrm{cm}$

- emulsion layer, thick enough to prevent the so-called stamp effect and thin enough to resist excessive wear, applied in a direct/indirect method

- the flatness is better than $5 \mu \mathrm{m}$ 's, measured along the edge of a screenwindow, so that no ink can be pressed between screen substrate.

Table I gives the results gained with some 230 and 325 mesh screens. The 325 mesh screens show better results than the thicker 230 mesh screens.

Inks In the left part of table II the variety in classification of the inks is obvious. A number of factors are important. From the start of the squeegee movement up to and including the sintering the inks have to endure the following influences:

- squeegee movement and meshsize (viscosity at shear rates between 100 and $1000 \mathrm{~s}^{-1}$ ) $/ 1 /$

- adhesive and cohesive forces (ink-substrate, ink-screen and internal ink respectively)

- surface tension and gravity in deposited ink columns

- shear stresses at shear rates between 100 and $0 \mathrm{~s}^{-1}$

- if present thixotropy

- evaporation of solvents.

During the squeegee movement the ink is pressed through the open meshes on the substrate. The viscosity should be low to have a good flow into and through the meshes and have a good separation of the ink from the screen. A too high viscosity will cause clogging. Preferably the viscosity should be between 50 and 70 Pas at a shear rate of $100 \mathrm{~s}^{-1}$. (See figure 1.)

Higher shear rates should cause lower viscosities. Adhesive and cohesive forces play a part in determining the amount of ink that will be deposited.

After the transfer stage, surface tension and gravity (ink column height and specific mass) act on the ink causing levelling and outflow. The velocity of flow is fixed by the rheological behaviour of the ink. The shear rates are low at this stage $\left(0.1 \mathrm{~s}^{-1}\right)$.

The relation between the spread of ink and acting surface tension in this situation is given by the expression 
FINER LINES IN THICK FILM CIRCUITRY

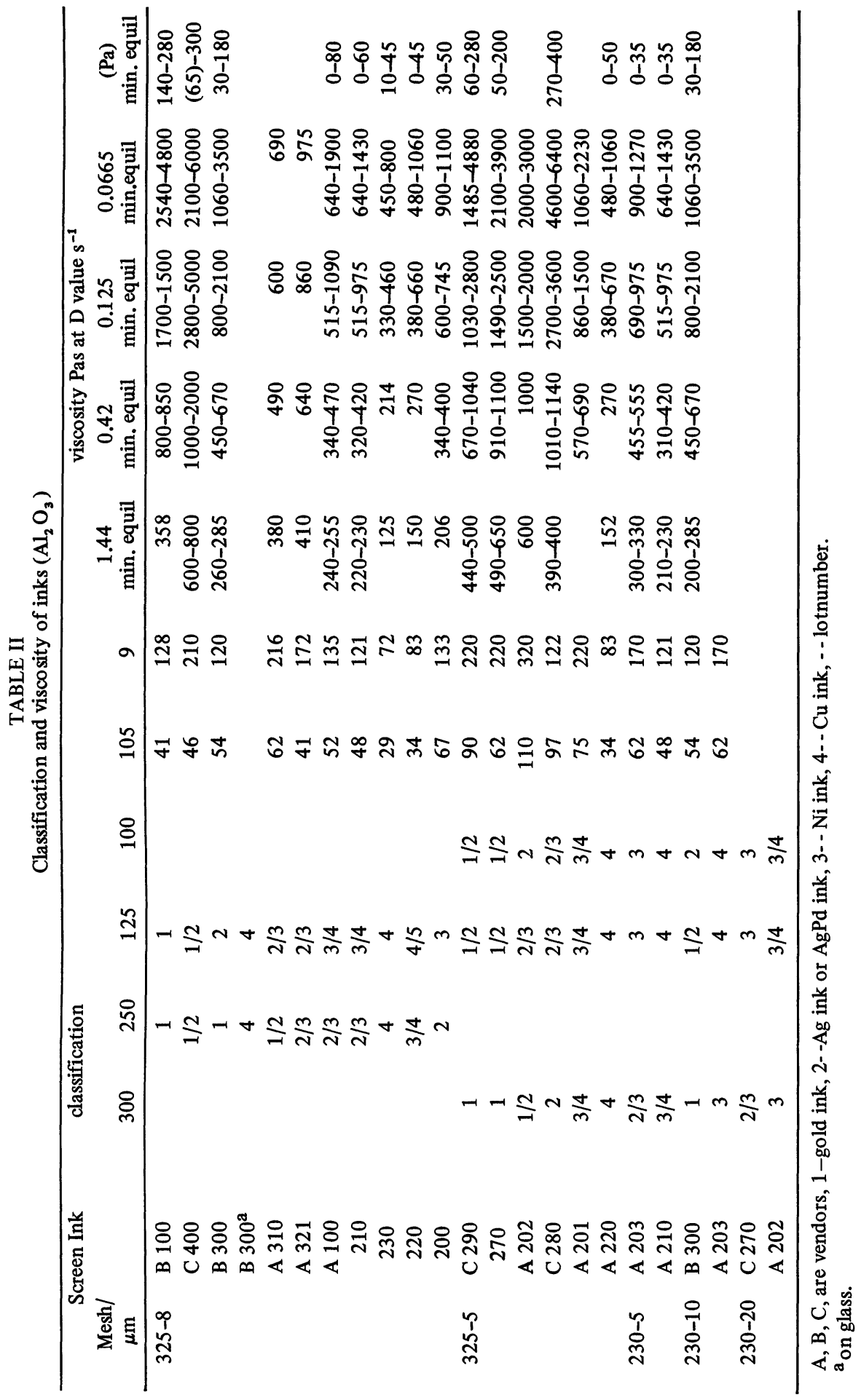




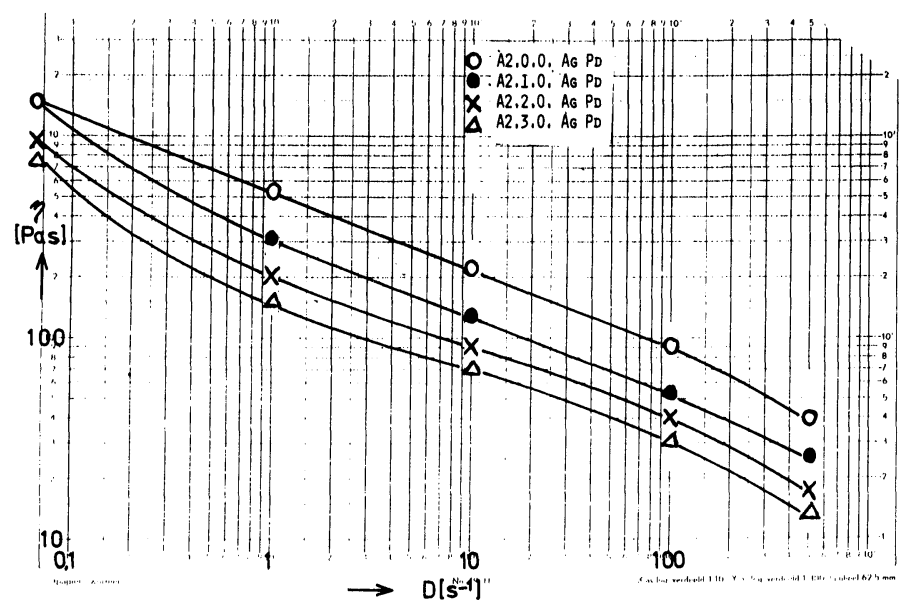

FIGURE 3 Rheogram of some inks

$$
\mathrm{S}_{\mathrm{C}}=\gamma_{\mathrm{SA}}-\left(\gamma_{\mathrm{SL}}+\gamma_{\mathrm{LA}}\right)
$$

$\gamma_{\mathrm{SA}}=$ surface tension of solid in air

$\gamma_{\mathrm{SL}}=$ interfacial tension of solid and liquid

$\gamma_{\mathrm{LA}}=$ surface tension of liquid in air.

$\mathrm{S}_{\mathrm{C}}>0$ results in complete coverage of the surface. For $\mathrm{S}_{\mathrm{C}}<0$ the liquid will spread until a contact angle is formed. For equilibrium according to Young the following equation is valid

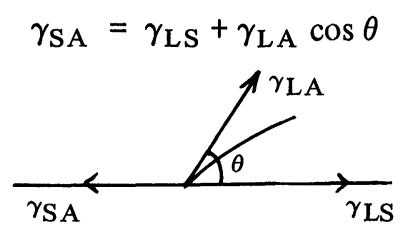

Thick film inks $\left(\gamma_{\mathrm{LA}} \sim 3-4 \times 10^{-2} \mathrm{~N} / \mathrm{cm}^{2}\right)$ should spread entirely over the surface of $\mathrm{Al}_{2} \mathrm{O}_{3}$ or glass $\left(\gamma_{\mathrm{SA}} \geqslant 40 \times 10^{-2} \mathrm{~N} / \mathrm{cm}^{2}\right)$. This is also valid for solvents as terpineol and butyl diglycolacetate.

Most inks seem to produce a contact angle of $20-40^{\circ} / 2 /$. Possibly the substrate is covered with a thin layer of ethylcellulose during the outlow owing to the evaporation of solvent. This causes ( $\gamma_{\mathrm{SA}}$ ethycell. $<\gamma_{\mathrm{SL}}$ solution) the outflow to stop. Table III gives bad result for cleaned surfaces and surfaces pretreated with Aethylcellulose.

TABLE III

Influence of pretreatment of substrate surface $\left(\mathrm{Al}_{2} \mathrm{O}_{3}\right)$ ink A 204

\begin{tabular}{lcccc}
\hline & $250 \mu \mathrm{m}$ & $125 \mu \mathrm{m}$ & $125 \mu \mathrm{m}$ & \\
Treatment & $\mathrm{L}-\mathrm{R}$ & $\mathrm{L}-\mathrm{R}$ & $\mathrm{L}-\mathrm{R}$ & Total average \\
\hline No (as delivered) & $3-3$ & $3-4$ & $4-3$ & $3 / 4$ \\
Fired at $850^{\circ} \mathrm{C}$ & $3-3$ & $3 / 4-4$ & $4-3 / 4$ & $3 / 4$ \\
Fired at $1100^{\circ} \mathrm{C}$ & $3-3$ & $3 / 4-4$ & $4-3 / 4$ & $3 / 4$ \\
Cleaned & $3-3$ & $3 / 4-4$ & $4-3 / 4$ & $3 / 4$ \\
Cleaned + surfactant & $1-1$ & $1-1$ & $1-1$ & 1 \\
Cleaned + Aethylcellulose & $3 / 4-3$ & $3 / 4-4$ & $4-3 / 4$ & $3 / 4$ \\
\hline
\end{tabular}




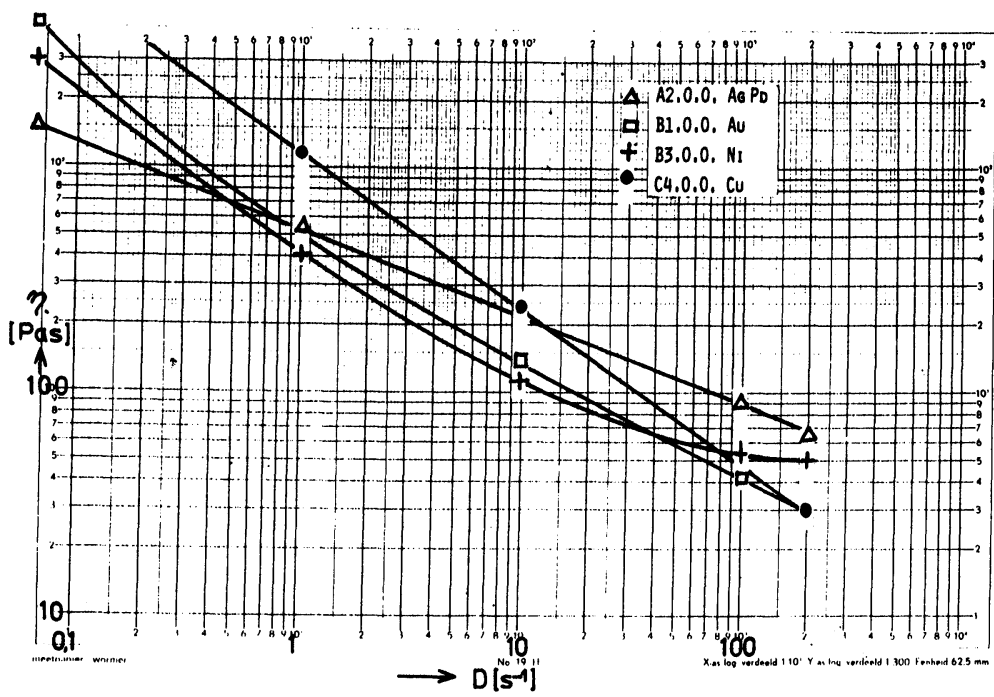

FIGURE 4 Rheogram of some inks

It is probably impossible to prevent the surface from becoming greasy. Pretreatment with a surfactant seems to be beneficial.

The part of gravity becomes clear from the fact that narrow lines and thicker layers spread more. The height/width ratio is larger than for wide lines (see below).

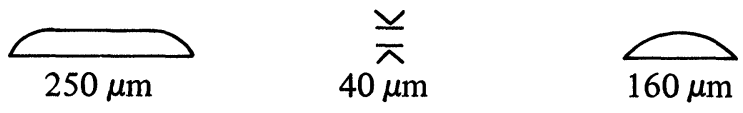

The driving force for the $160 \mu \mathrm{m}$ line is higher.

The velocity of the outflow is described by the formula $\mathrm{V}=\mathrm{S}_{\mathrm{C}} / \eta \times \mathrm{K}$.

$\mathrm{S}_{\mathrm{C}}$ (the coefficient of spread) is constant and $\mathrm{K}$ also (related to substrate roughness and layer thickness).

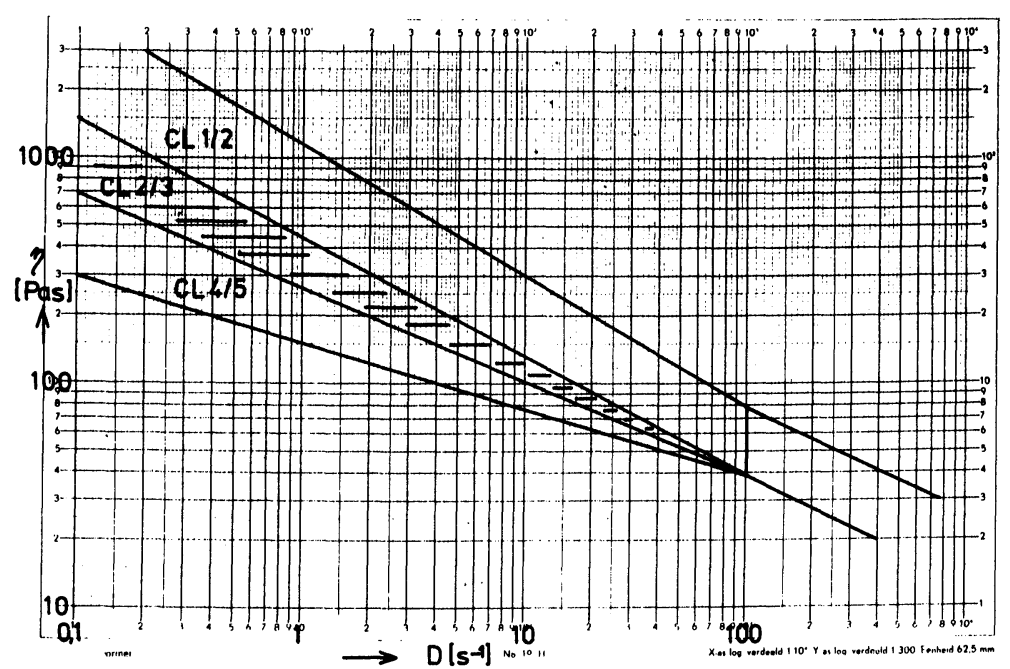

FIGURE 5 Classification regions 
$\eta$ determines the velocity of the outflow.

$-\eta$ depends on the shear rates (in this stage $\mathrm{D} \ll 1 \mathrm{~s}^{-1}$ )

$-\eta$ rises in course of time for thixotropic materials (fig. 3)

$-\eta$ rises because of the evaporation of solvent.

For the inks under consideration the viscosity at low shear rate is a very important factor. In this range three distinct properties are functioning:

a) the viscosity under equilibrium conditions

b) the velocity with which thixotropy and relaxation are built up

c) the numerical value of the yield value $\left(\tau_{0}\right)$.

As a characteristic for this range the value of $\eta$ at $D=0.1 \mathrm{~s}^{-1}$ could be taken.

ad a) For the inks under consideration the viscosities under equilibrium conditions are plotted against the shear rates.

See e.g. Figure 3 and Figure 4.

From these plots viscosity values at specific shear rates are combined with classification values of the inks in Table $I$.

High viscosity values correlate with good quality printing. The following classification limits are considered:

class 1 or $2 \eta>1500$ Pas

class 2 or $3700<\eta<1500$

class 3 or $4300<\eta<700$

Resulting in diagram (Figure 5).

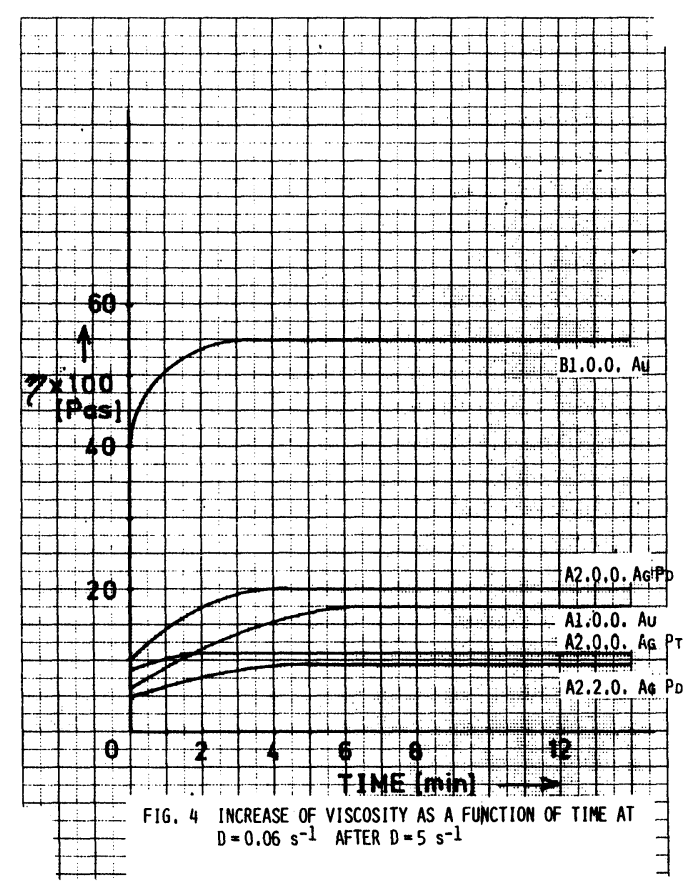

FIGURE 6 Increase of viscosity as a function of time at $\mathrm{D}=0.06 \mathrm{~s}^{-1}$ after $\mathrm{D}=5 \mathrm{~s}^{-1}$ 
These results are more or less specific for the organic binder and solvent ingredients of these commercial inks.

The deviative results found for $\mathrm{Ag}$ and $\mathrm{Ni}$ inks can be related to the difference in binder solution constituents of these inks.

ad b) The outflow happened, particularly, in the first minutes, so that the equilibrium value could not be reached in practice. At these moments, the minimum viscosity and the built up velocity of the thixotropy are important. Figure 6 shows that for the ink with the better resolution the minimum viscosity is higher and the built up of the thixotropy is faster.

ad c) the presence of a yield value promotes the line resolution. The determination is not simple when thixotropic effects are present.

To overcome this problem, the increase in viscosity between the shear rates of 1 and $0.1 \mathrm{~s}^{-1}$ can be used as a substitute criterium.

From the curves follows: class $1 \frac{d \log \eta}{d \log D}>/ 0.6 /$

$$
\begin{aligned}
& \text { class } 2 \frac{d \log \eta}{d \log D}>/ 0.5 / \\
& \text { class } 3 \frac{d \log \mu}{d \log D}>/ 0.4 /
\end{aligned}
$$

Dry and sinter conditions Strictly speaking levelling and drying are in line with one another. It is obvious that drying, as a process to remove the solvent inside the conductor, must start at room temperature without causing eruptions. An end temperature of $120^{\circ} \mathrm{C}$ for 15 minutes is sufficient. Doing it this way no line widening contribution is found. Sintering does not cause line widening at all.

Summarizing, it can be said that for this type of inks the rheogram for low shear rates can help to predict the fine line capabilities.

\section{CONCLUSIONS}

- For the investigated type of inks the rheogram can predict the fine line capabilities.

- A slightly calendered metal gauze screen stretched under $45^{\circ}$ with the frame, with a homogeneous tension between 20 and $30 \mathrm{~N} / \mathrm{cm}$, preferably 325 mesh, with a thin flat emulsion layer gives the best results.

- As a quick evaporation of the solvent can be beneficial an adequate levelling condition must be emphasized.

\section{ACKNOWLEDGEMENT}

The author wish to thank Mrs. Beurskens-Nijssen, Mr. Sleutjes and Mrs. Vrolijks for their work and assistance in preparing samples, measuring the results and the preparation of the screens.

\section{REFERENCES}

1. R.E. Trease and R.L. Dietz "Rheology of pastes for thick film printing," Solid State Technology, p. 39-43 (Jan. 1972).

2. J.R. Larry "Influence of surface energies on line resolution in screenprinting", Solid State Technology, p. 18-48 (June 1972). 

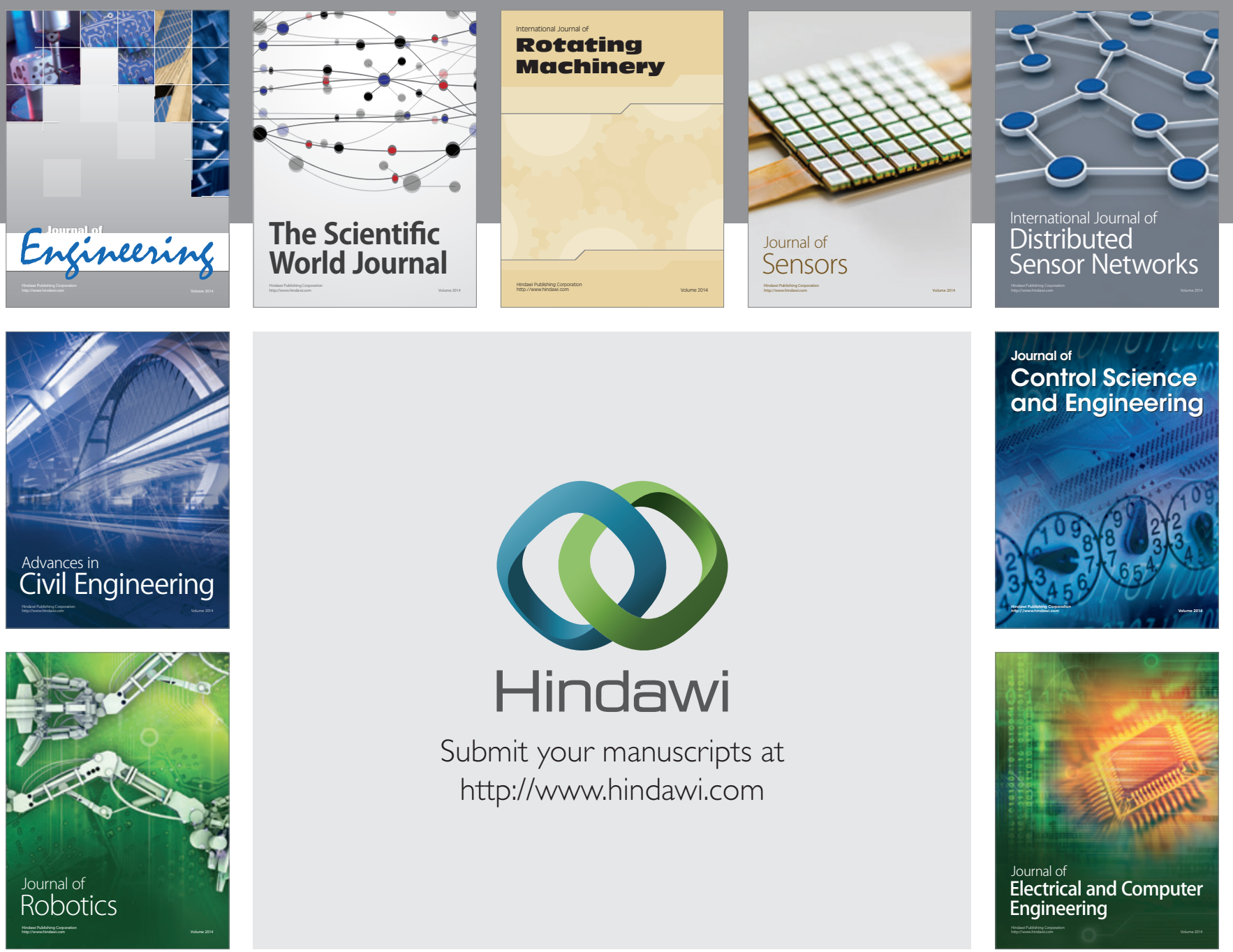

Submit your manuscripts at

http://www.hindawi.com
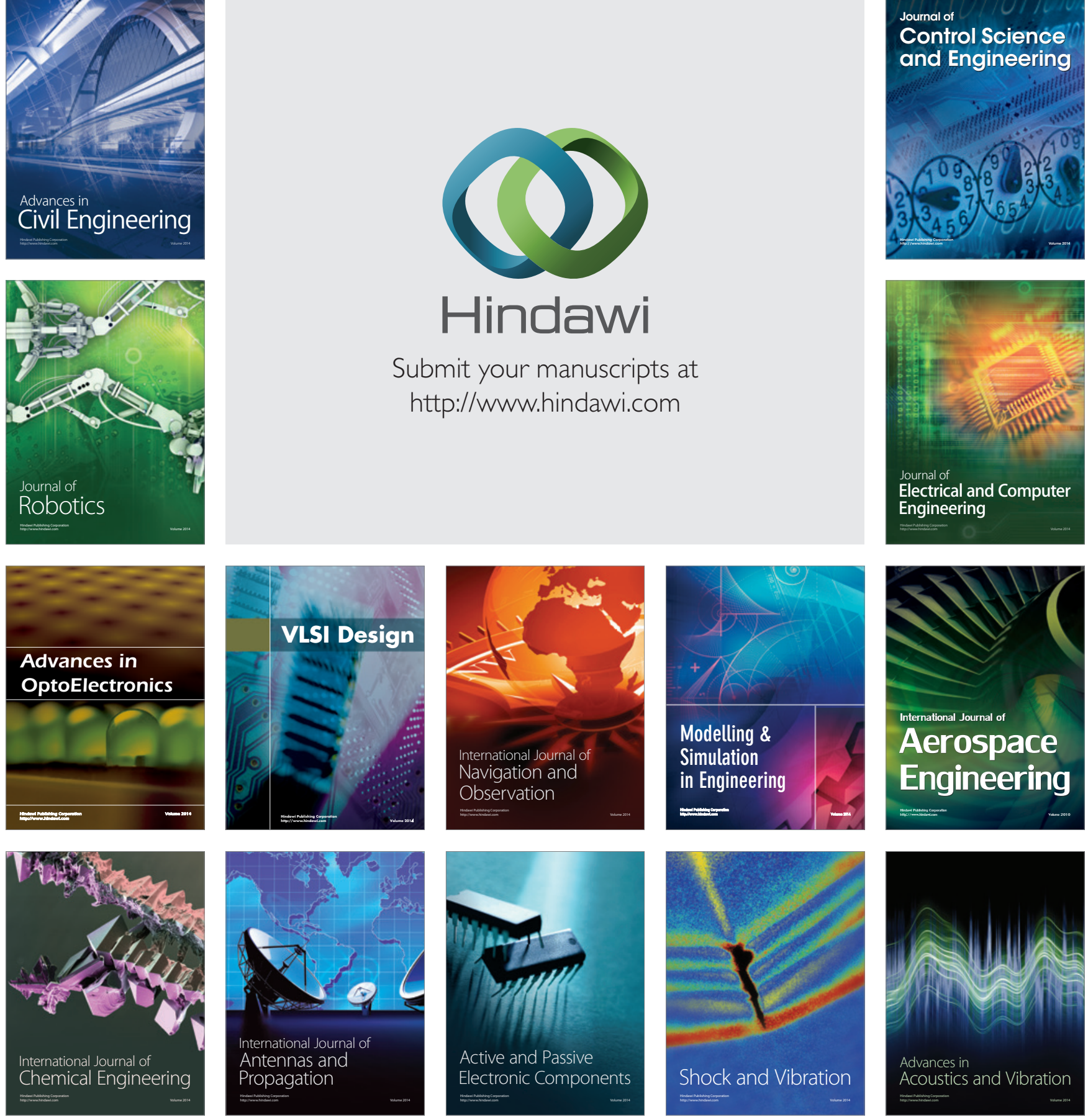